\title{
Measurement of Mean Carotid Artery Intima Media Thickness in Patients of Diabetes Mellitus and Metabolic Syndrome
}

\author{
Nutan Agarwal ${ }^{1}$, Rajat Jain², Pallavi Agarwal ${ }^{3}$, Dinesh Kumar Raina ${ }^{4}$, Gauri Naryani ${ }^{5}$, Swati Azad ${ }^{6}$ \\ ${ }^{1}$ Professor, Department of Medicine, MLB Medical College, Jhansi, Uttar Pradesh, India. ${ }^{2}$ Associate Professor, \\ Department of Medicine, MLB Medical College, Jhansi, Uttar Pradesh, India. ${ }^{3}$ Associate Professor, Department of \\ Pathology, MLB Medical College, Jhansi, Uttar Pradesh, India. ${ }^{4}$ Resident, Department of Medicine, MLB Medical \\ College, Jhansi, Uttar Pradesh, India. ${ }^{5}$ Medical Student, MLB Medical College, Jhansi, Uttar Pradesh, India. ${ }^{6}$ Medical \\ Student, MLB Medical College, Jhansi, Uttar Pradesh, India.
}

\section{ABSTRACT}

\section{BACKGROUND}

Diabetes mellitus is associated with various microvascular and macrovascular complications. It has been suggested that the atherosclerotic process occurs at the same time in carotid, cerebral and coronary arteries.(1) In our study, we measured the carotid artery intima media thickness in patients of diabetes mellitus and metabolic syndrome. We also tried to determine the effect of duration of diabetes on carotid artery intima media thickness.

\section{METHODS}

Our study was cross sectional study conducted on 200 patients of diabetes mellitus and metabolic syndrome who presented to the out-patient and in-patient departments at the Department of Medicine, MLB Medical College, Jhansi (UP) over a period of 17 months, from June 2017 to October 2018. 100 non-diabetic and nonmetabolic syndrome patients were taken as controls. Ultrasonography was performed with B-mode images of a high-resolution ultrasound scanner equipped with $7 \mathrm{MHz}$ linear array transducer. The mean CIMT was compared with various variables like diabetes and its types and duration, hypertension, age, sex, body mass index, glycosylated haemoglobin (HbA1c), dyslipidaemia, microvascular complications (like nephropathy and neuropathy) and other risk factors.

\section{RESULTS}

Out of the 300 subjects of our study, 179 were males (93 diabetic, 26 metabolic syndrome and 60 controls) and 121 females (65 diabetic, 16 metabolic syndrome and 40 controls). So, the male: female ratio in our study was 1.48:1, with maximum number $(41.77 \%)$ of patients falling in 46-60 years age. The mean CIMT was found in general to increase with age, and significantly more in diabetic patients $(0.791 \pm 0.261 \mathrm{~mm})$ and metabolic syndrome patients $(0.726 \pm 0.218 \mathrm{~mm})$ than the controls $(0.645 \pm 0.135 \mathrm{~mm})$. While in diabetic patients it was observed that males had higher mean CIMT $(0.84 \pm 0.26 \mathrm{~mm})$, in the metabolic syndrome group of patients, females had a greater value of mean CIMT $(0.74 \pm 0.19 \mathrm{~mm})$. It was observed that the mean CIMT values increased proportionately with the duration of diabetes.

\section{CONCLUSIONS}

Carotid artery intima media thickness correlates positively and strongly with age, sex, body mass index, duration of diabetes. Therefore, mean CIMT appears to us as a surrogate marker of coronary atherosclerosis. Thus, we propose that mean CIMT should be measured in all diabetic and metabolic syndrome patients to screen them for possible complications of atherosclerosis, so that timely measures can be taken.

\section{KEY WORDS}

Diabetes Mellitus, Metabolic Syndrome, Atherosclerosis, Carotid Artery, Intima Media Thickness
Corresponding Author: Dr. Rajat Jain,

Associate Professor, Department of Medicine, MLB Medical College, Jhansi, Uttar Pradesh, India. E-mail: abha.jain2811@gmail.com

DOI: 10.14260/jemds/2019/649

Financial or Other Competing Interests: None.

How to Cite This Article: Agarwal N, Jain R, Agarwal $P$, et al. Measurement of mean carotid artery intima media thickness in patients of diabetes mellitus and metabolic syndrome. J. Evolution Med. Dent. Sci. 2019;8(39): 2986-2990 DOI: 10.14260/jemds/2019/649

Submission 09-07-2019, Peer Review 10-09-2019, Acceptance 17-09-2019, Published 30-09-2019.

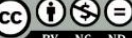




\section{BACKGROUND}

Diabetes mellitus is associated with various microvascular and macrovascular complications. It has been suggested that the atherosclerotic process occurs at the same time in carotid, cerebral and coronary arteries.(1) The disease burden of diabetes mellitus is high and rising in India. It is fuelled by the rise in prevalence of obesity and unhealthy lifestyles. Diabetes has two types of complications- Microvascular and Macrovascular. Microvascular complications include nephropathy, neuropathy and retinopathy. Macrovascular complications are stroke, coronary artery disease, peripheral vascular disease etc. and atherosclerosis is implicated as the major determinant in causing these complications.

Metabolic syndrome has its own complications, which include diabetes mellitus type II, high cholesterol, high blood pressure contributing to development of plaques in arteries, which can lead to coronary artery disease and stroke.

The most important change in early subclinical period of atherosclerotic disease are endothelial dysfunction and increase in intima media thickness observed in all arterial beds.(2)(3) Thickening of arterial wall of the common carotid artery and plaque formation at the carotid bifurcation are observed, and atherosclerosis, especially carotid atherosclerosis is a known cause of stroke.(4)

Atherosclerosis in the carotid arteries has been found to be associated with cerebrovascular accidents which are associated with adverse outcomes in terms of morbidity and mortality.(5),(6)

It has been suggested by the international atherosclerotic risk project that the atherosclerotic process occurs at the same time in carotid, cerebral and coronary arteries.(1) The intima media thickness of carotid artery can be measured with a high degree of accuracy and reproducibility by B-mode ultrasonography which provides a reliable and valid estimate of arterial wall thickness. So, carotid intima media thickness test (CIMT) can be used to diagnose the extent of carotid atherosclerotic vascular disease.

\section{METHODS}

\section{Study Design}

Our study was a cross sectional study, approved by the Ethical committee of Maharani Laxmi Bai Medical College, Jhansi. All the patients provided informed consent before undergoing the study. The Medicine department of MLB medical college supported the study; no industry support was included.

\section{Data Source and Study Cohort}

The study was conducted on 200 patients of diabetes mellitus and metabolic syndrome who presented to the out-patient and in-patient departments of MLB medical college between June 2017 and October 2018. 100 patients without diabetes mellitus and metabolic syndrome were taken as controls. Sample size was taken based on the convenience of the study. Sample size was taken based on the convenience of the study.

Diabetes was diagnosed in patients presenting with fasting blood glucose $\geq 126 \mathrm{mg} \%$, or post-prandial blood glucose $\geq 200 \mathrm{mg} \%$ on two occasions with classical symptoms, or $\mathrm{HbA} 1 \mathrm{c} \geq 6.5 \%$.(7)

Metabolic syndrome was diagnosed on the basis of presence of any three of the following features: central obesity (Waist circumference $>102 \mathrm{~cm}$ in males, $>88 \mathrm{~cm}$ in females); hypertriglyceridemia (Triglyceride level $>150$ $\mathrm{mg} / \mathrm{dl})$; low HDL cholesterol $(<40 \mathrm{mg} / \mathrm{dl}$ in males, $50 \mathrm{mg} / \mathrm{dl}$ in females); hypertension (BP $>130 / 85 \mathrm{mmHg}$ ) and fasting plasma glucose level $\geq 100 \mathrm{mg} / \mathrm{dl}$ or previous diagnosed type II diabetes. The patients who refused to participate in the study and known cases of valvular heart disease were excluded from this study.

Patients were divided into 3 groups-

- Group A: diabetic patients without metabolic syndrome $(\mathrm{N}=158)$

- Group B: patients with metabolic syndrome $(\mathrm{N}=42)$

- Group C: control patients $(\mathrm{N}=100)$.

\section{Procedure at Baseline}

Carotid artery ultrasound examination was performed with the patient supine, the neck slightly extended, and the head turned away from the side being examined. The examination sequence included the Gray scale examination and colour Doppler blood flow interrogation. Colour Doppler flow imaging was performed with 5-10 MHz transducers.

Gray scale sonography examination begins in transverse position. Scans were obtained along the entire course of cervical carotid artery, from supraclavicular notch to the angle of mandible. Transverse views of the carotid bifurcation established the orientation of the external and internal carotid arteries and helps define the optimal longitudinal plane in which to perform Doppler analysis.

After transverse imaging, longitudinal scans of the carotid artery were obtained. The examination plane necessary for optimal longitudinal scan is determined by the course of the vessels demonstrated on transverse study.

Arterial diameter and mean CIMT measurements were done three times for each artery on each side. The average of the three of each carotid artery diameter or CIMT was taken.

\section{Statistical Analysis}

Stratified sampling was done. Data collected was entered into Excel. Chi-square and Fischer's exact test were done for qualitative data. Unpaired $t$ test and ANOVA were done to identify selected risk factors for the outcome.

\section{RESULTS}

In our study total 179 male (93 diabetic, 26 metabolic syndromes and 60 controls) and 121 female (65 diabetic, 16 metabolic syndromes and 40 controls) patients were included. So the male: female ratio in this study was 1.48:1

\begin{tabular}{|c|c|c|c|}
\hline & No. of Patients & Male & Female \\
\hline Diabetic Group & 158 & $93(58.86 \%)$ & $65(41.14 \%)$ \\
\hline Metabolic syndrome Group & 42 & $26(61.90 \%)$ & $16(38.10 \%)$ \\
\hline Control Group & 100 & $60(60 \%)$ & $40(40 \%)$ \\
\hline Total & $\mathbf{3 0 0}$ & $\mathbf{1 7 9}(\mathbf{5 9 . 6 7 \% )})$ & $\mathbf{1 2 1}(40.33 \%)$ \\
\hline \multicolumn{3}{|r}{ Table 1. Gender Wise Distribution } \\
\hline
\end{tabular}

In the diabetic group there were 93 males (58.86\%) and 65 females (41.14\%). In the metabolic syndrome group, there 
were 26 males (61.90\%) and 16 females (39.10\%). In the control group there were 60 males $(60 \%)$ and 40 females $(40 \%)$.

\begin{tabular}{|c|c|c|c|c|}
\hline $\begin{array}{c}\text { Age Group } \\
\text { (Yrs.) }\end{array}$ & $\begin{array}{c}\text { Diabetes } \\
\text { Group }\end{array}$ & $\begin{array}{c}\text { Metabolic } \\
\text { Syndrome Group }\end{array}$ & $\begin{array}{c}\text { Control Patients } \\
\text { Group }\end{array}$ & $\begin{array}{c}\text { No. of Patients } \\
\text { (\%) }\end{array}$ \\
\hline $15-30$ & $11(6.96 \%)$ & $06(14.29 \%)$ & $21(21.00 \%)$ & $38(12.67 \%)$ \\
\hline $31-45$ & $24(15.19 \%)$ & $06(14.29 \%)$ & $27(27.00 \%)$ & $57(19.00 \%)$ \\
\hline $46-60$ & $66(41.77 \%)$ & $17(40.48 \%)$ & $34(34.33 \%)$ & $117(39.00 \%)$ \\
\hline $61-75$ & $43(27.22 \%)$ & $08(19.04 \%)$ & $14(14.00 \%)$ & $65(21.67 \%)$ \\
\hline$>75$ & $14(8.86 \%)$ & $05(11.90 \%)$ & $04(04.00 \%)$ & $23(07.67 \%)$ \\
\hline Total & $\mathbf{1 5 8}(\mathbf{5 2 . 6 7 \% )}$ & $\mathbf{4 2}(\mathbf{1 4 \% )}$ & $\mathbf{1 0 0}(\mathbf{3 3 . 3 3 \% )}$ & $\mathbf{3 0 0 ( 1 0 0 \% )}$ \\
\hline \multicolumn{5}{|c|}{ Table 2. Age Wise Distribution of Patients } \\
\hline
\end{tabular}

Majority of diabetic patients (66 out of 158 i.e. $41.77 \%$ ) fall in age group of 46-60 years followed by 61-75 years (43 out of 158 i.e. $27.22 \%$ ). Similarly, majority of patient with metabolic syndrome lie under 46-60 years age group (17 out of 42 i.e. $40.48 \%$ ). Least number of patients in all three groups were in $<30$ and $>75$ years age group.

\begin{tabular}{|c|c|c|c|}
\hline \multirow{2}{*}{$\begin{array}{c}\text { Age Group } \\
\text { (in Years) }\end{array}$} & $\begin{array}{c}\text { Diabetic } \\
\text { Group }\end{array}$ & $\begin{array}{c}\text { Metabolic } \\
\text { Syndrome Group }\end{array}$ & $\begin{array}{c}\text { Control } \\
\text { Group }\end{array}$ \\
\cline { 2 - 4 } & $0.57 \pm 0.24$ & $0.47 \pm 0.21$ & $0.58 \pm 0.14$ \\
\hline $15-30$ & $0.72 \pm 0.23$ & $0.63 \pm 0.01$ & $0.63 \pm 0.14$ \\
\hline $31-45$ & $0.79 \pm 0.25$ & $0.82 \pm 0.22$ & $0.65 \pm 0.13$ \\
\hline $46-60$ & $0.84 \pm 0.26$ & $0.66 \pm 0.19$ & $0.74 \pm 0.14$ \\
\hline $61-75$ & $0.93 \pm 0.27$ & $0.90 \pm 0.22$ & $0.74 \pm 0.82$ \\
\hline$>75$ & \multicolumn{3}{|c|}{ Table 3. Distribution of Mean CIMT in Studied Age Groups } \\
\hline \multicolumn{3}{|c}{} \\
\hline
\end{tabular}

In our study, we observed that mean CIMT was lowest in the age group of 15-30 years and was the highest in $>75$ years age group irrespective of diabetes and metabolic syndrome. Mean CIMT was found to progressively increase with age in diabetic, metabolic syndrome and control groups.(7),(8) But in the metabolic syndrome group, the rise in CIMT with age was not uniform. It might be because of small sample size.

\begin{tabular}{|c|c|c|}
\hline Groups & Mean \pm SD & $\begin{array}{c}\text { p-Value } \\
\text { (As Compared to Control) }\end{array}$ \\
\hline Diabetes group & $0.791 \pm 0.261$ & 0.0001 \\
\hline Metabolic syndrome group & $0.726 \pm 0.218$ & 0.0080 \\
\hline Control group & $0.645 \pm 0.135$ & - \\
\hline \multicolumn{2}{|c|}{ Table 4. Comparison of Mean CIMT in Study Groups } \\
\hline
\end{tabular}

Mean CIMT was significantly higher in diabetic patients $(0.791 \pm 0.261)$ and metabolic syndrome $(0.726 \pm 0.218)$ than control cases $(0.645 \pm 0.135)$.

The mean CIMT of diabetic patients was higher than the metabolic syndrome patients but this difference was not found to be statistically significant.

In our study, diabetic male patients had mean CIMT of $0.84 \pm 0.26 \mathrm{~mm}$ which was greater than diabetic females who had a mean CIMT of $0.72 \pm 0.26 \mathrm{~mm}$ [statistically significant]. In case of metabolic syndrome, female patients had greater mean CIMT value $(0.74 \pm 0.19)$ than the male patients $(0.72 \pm 0.22)$ [statistically non-significant]. The control group showed higher mean CIMT in male patients $(0.65 \pm 0.14)$ than the female patients $(0.63 \pm 0.13)$.
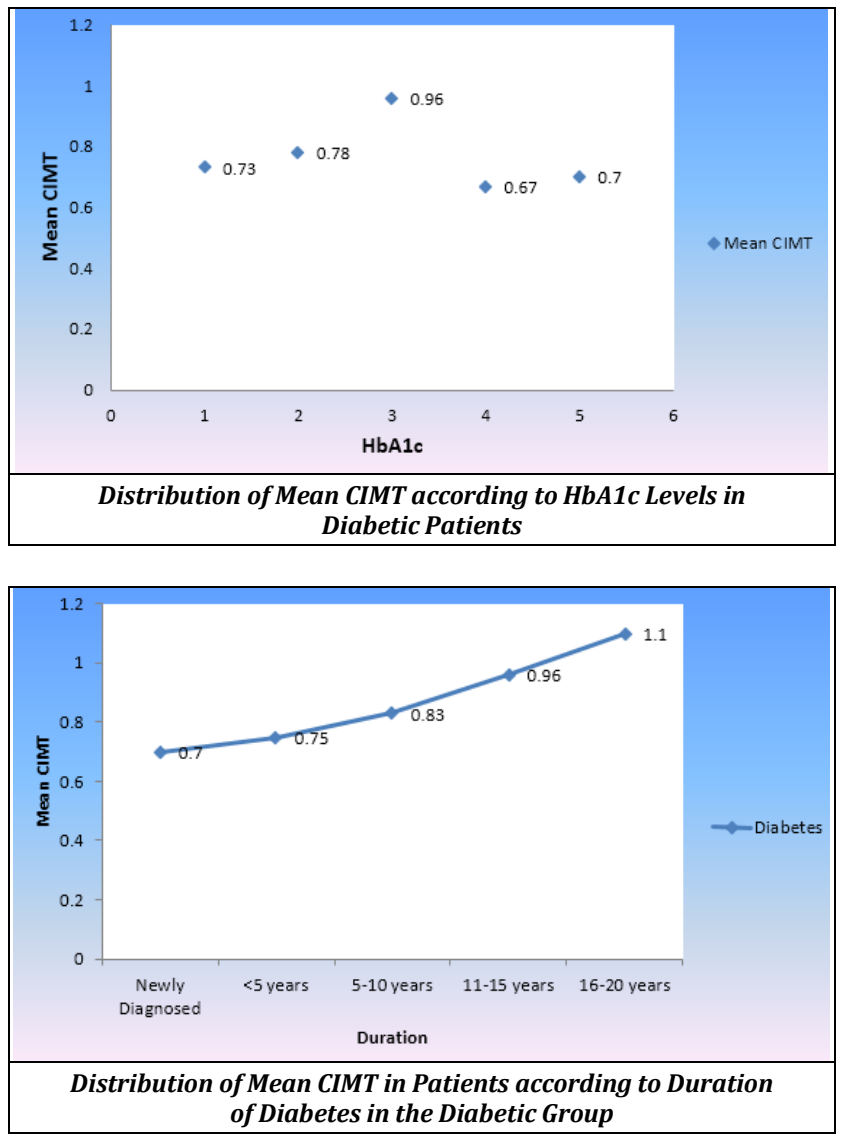

Patients with $<5$ years of diabetes mellitus had minimum mean CIMT $(0.75 \pm 0.26 \mathrm{~mm})$, followed by $5-10$ years $(0.83 \pm 0.26 \mathrm{~mm}), 11-15$ years $(0.96 \pm 0.24 \mathrm{~mm})$ and then $>15$ years $(1.1 \pm 0.26)$. Thus, the mean CIMT increases proportionately with the increase in duration of diabetes.

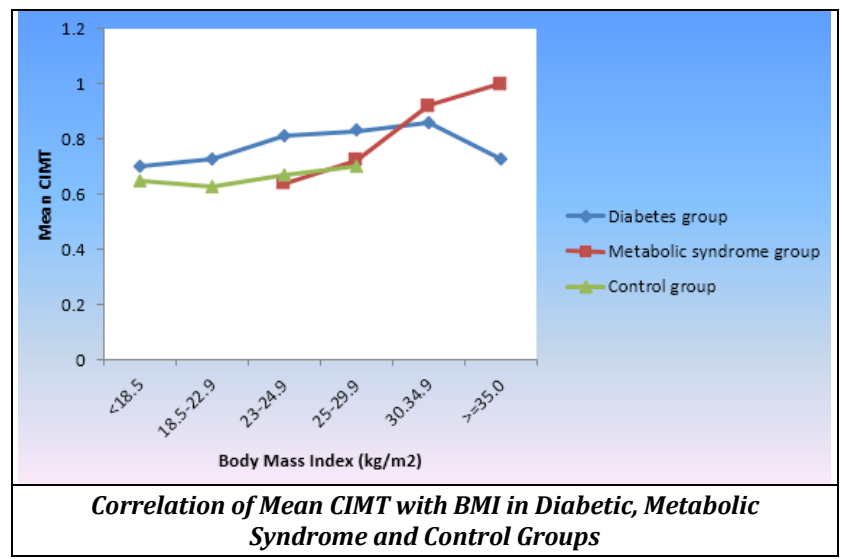

Patients in all groups were subcategorized according to BMI. In diabetic group, minimum CIMT was found in patients who had $\mathrm{BMI}<18.5 \mathrm{Kg} / \mathrm{m}^{2}$ (i.e. $0.70 \pm 0.12 \mathrm{~mm}$ ), similarly in metabolic syndrome group, minimum CIMT was found in patients having BMI $23-24.9 \mathrm{Kg} / \mathrm{m}^{2}$ (i.e. $0.64 \pm 0.18 \mathrm{~mm}$ ). Maximum CIMT in diabetic group was found in patients with BMI $30-34.9 \mathrm{Kg} / \mathrm{m}^{2}$ (i.e. $0.86 \pm 0.39 \mathrm{~mm}$ ), similarly in metabolic syndrome group the maximum mean CIMT was in patients with BMI $\geq 35 \mathrm{Kg} / \mathrm{m}^{2}$ (i.e. $1.0 \pm 0.14 \mathrm{~mm}$ ). Thus, the trend shows that the mean CIMT increases with BMI. 


\begin{tabular}{|c|c|c|c|c|c|c|}
\hline \multirow{2}{*}{$\begin{array}{c}\text { Serum } \\
\text { Creatinine }\end{array}$} & \multicolumn{2}{|c|}{ Diabetic Group } & \multicolumn{2}{c|}{$\begin{array}{c}\text { Metabolic } \\
\text { Syndrome Group }\end{array}$} & \multicolumn{2}{c|}{ Control Group } \\
\cline { 2 - 7 } & $\begin{array}{c}\text { No. of } \\
\text { Patients }\end{array}$ & $\begin{array}{c}\text { Mean } \\
\text { CIMT } \pm \text { SD }\end{array}$ & $\begin{array}{c}\text { No. of } \\
\text { Patients }\end{array}$ & $\begin{array}{c}\text { Mean } \\
\text { CIMT } \pm \text { SD }\end{array}$ & $\begin{array}{c}\text { No. of } \\
\text { Patients }\end{array}$ & $\begin{array}{c}\text { Mean } \\
\text { CIMT } \pm \text { SD }\end{array}$ \\
\hline$\leq 1.2(\mathrm{mg} \%)$ & 68 & $0.73 \pm 0.22$ & 22 & $0.62 \pm 0.22$ & 92 & $0.64 \pm 0.14$ \\
\hline 1.3 to $2.5(\mathrm{mg} \%)$ & 49 & $0.79 \pm 0.21$ & 09 & $0.76 \pm 0.10$ & 05 & $0.64 \pm 0.15$ \\
\hline 2.6 to $4.0(\mathrm{mg} \%)$ & 28 & $0.87 \pm 0.35$ & 05 & $0.86 \pm 0.19$ & 03 & $0.73 \pm 0.06$ \\
\hline $4.0(\mathrm{mg} \%)$ & 13 & $0.91 \pm 0.33$ & 06 & $0.95 \pm 0.12$ & - & - \\
\hline & Table 5. Comparison of Mean CIMT with S. Creatinine \\
\hline
\end{tabular}

According to the above table, minimum mean CIMT in diabetic group, metabolic syndrome group and control group was $0.73 \pm 0.22 \mathrm{~mm}, 0.62 \pm 0.22 \mathrm{~mm}$ and $0.64 \pm 0.14 \mathrm{~mm}$ respectively in patients having serum creatinine $<1.2 \mathrm{mg} \%$. the maximum mean CIMT was found in patients who had higher serum creatinine levels in all three groups ( i.e. diabetic $0.91 \pm 0.33 \mathrm{~mm}$, metabolic syndrome $0.95 \pm 0.12$ $\mathrm{mm}$, control $0.73 \pm 0.06 \mathrm{~mm}$ ). Thus, the mean CIMT increases with serum creatinine level, irrespective of the study groups (statistically non-significant).

\begin{tabular}{|c|c|c|c|c|c|c|}
\hline \multirow{2}{*}{$\begin{array}{c}\text { Dys- } \\
\text { lipidemia }\end{array}$} & \multicolumn{2}{|c|}{ Diabetic Group } & \multicolumn{2}{c|}{$\begin{array}{c}\text { Metabolic } \\
\text { Syndrome Group }\end{array}$} & \multicolumn{2}{c|}{ Control Group } \\
\cline { 2 - 7 } & $\begin{array}{c}\text { Present } \\
(\mathbf{9 5 )}\end{array}$ & $\begin{array}{c}\text { Absent } \\
\mathbf{( 6 3 )}\end{array}$ & $\begin{array}{c}\text { Present } \\
\mathbf{( 4 2 )}\end{array}$ & $\begin{array}{c}\text { Absent } \\
\mathbf{( 0 )}\end{array}$ & $\begin{array}{c}\text { Present } \\
\mathbf{( 9 )}\end{array}$ & $\begin{array}{c}\text { Absent } \\
\mathbf{( 9 1 )}\end{array}$ \\
\hline Mean CIMT & $0.79 \pm 0.26$ & $0.78 \pm 0.25$ & $0.726 \pm 0.22$ & - & $0.66 \pm 0.14$ & $0.64 \pm 0.14$ \\
\hline p-value & \multicolumn{3}{|c|}{0.8104} & \multicolumn{3}{c}{0.6836} \\
\hline \multicolumn{3}{r}{ Table 6. Correlation of Mean CIMT and Dyslipidemia } \\
\hline
\end{tabular}

The diabetic patients with dyslipidaemia had greater mean CIMT as compared to the diabetic group with normal lipid profile. The same result was found in control group. In metabolic syndrome group there was no patient without dyslipidaemia.

\begin{tabular}{|c|c|c|}
\hline & $\begin{array}{c}\text { Hypertensive (133) } \\
\{44.33 \%\} \\
\end{array}$ & $\begin{array}{c}\text { Normotensive (167) } \\
\{55.67 \%\} \\
\end{array}$ \\
\hline Mean CIMT \pm SD & $0.76 \pm 0.22$ & $0.71 \pm 0.24$ \\
\hline p-value & \multicolumn{2}{|c|}{0.0639} \\
\hline
\end{tabular}

The subjects in our study were divided into 2 groups according to their blood pressure. The hypertensive group had higher mean CIMT as compared to the normotensive group, but the p-value was insignificant (It might be due to small sample size).

\section{DISCUSSION}

The study was conducted at the Department of Medicine, Maharani Laxmi Bai Medical College, Jhansi (U. P.) from June 2017 to October 2018. Total 300 individuals who fulfilled the inclusion criteria were included. According to the inclusion and exclusion criteria, the subjects were divided into 3 groups: Group A- Diabetic patients without metabolic syndrome $(\mathrm{N}=158)$; Group $\mathrm{B}-$ patients with metabolic syndrome ( $\mathrm{N}=42)$; Group $\mathrm{C}$ - control patients without diabetes and metabolic syndrome $(\mathrm{N}=100)$.

In all the patients, clinical examination, risk factors, investigations and assessment for various complications was done. Thereafter ultrasound examination was done, and carotid intimal thickness was measured.

In our study, the mean CIMT in diabetic patients $(0.791 \pm 0.261 \mathrm{~mm})$ and metabolic syndrome's patients $(0.726 \pm 0.218 \mathrm{~mm})$ was found to be higher as compared to control patients $(0.645 \pm 0.135 \mathrm{~mm})$. The mean CIMT was also found to increase with age.(8),(9) In the diabetic group, male patients had higher mean CIMT $(0.84 \pm 0.26 \mathrm{~mm})$ as compared to the female patients $(0.72 \pm 0.26 \mathrm{~mm}),{ }^{(10)}$ and similar result was found in control group as well. But, in case of metabolic syndrome,(11) the female patients had higher mean CIMT $(0.74 \pm 0.19 \mathrm{~mm})$ as compared to male patients $(0.72 \pm 0.22$ $\mathrm{mm})$. The mean CIMT also increased with the increase in duration of diabetes,(12) but had a poor correlation with glycosylated haemoglobin. We also noticed that mean CIMT was higher in those individuals who had higher BMI. In our study, the hypertensive patients of all the three groups had increased mean CIMT as compared to the normotensive patients. We also found a positive correlation between increase serum creatinine and mean CIMT in all the study groups. In our study, in the diabetic group, the mean CIMT was found to be slightly increased in patients with dyslipidaemia $(0.79 \pm 0.26 \mathrm{~mm})$ as compared to the patients with normal lipid profile. Also, in the control group, the mean CIMT was higher in those with dyslipidaemia $(0.66 \pm 0.14$ $\mathrm{mm}$ ). Thus, we can say that dyslipidaemia is an independent risk factor for increasing mean CIMT. Mean CIMT was higher in subjects with addiction $(0.81 \pm 0.26 \mathrm{~mm})$ in the form of smoking, tobacco chewing or alcohol abuse as compared to those without addiction $(0.77 \pm 0.23 \mathrm{~mm})$.

\section{CONCLUSIONS}

Carotid artery intima media thickness correlates positively and strongly with age, sex, body mass index, duration of diabetes and additional risks of diabetes like high body mass index, dyslipidaemia, hypertension, serum creatinine, addictions etc. Therefore, mean CIMT appears to us as a surrogate marker of coronary atherosclerosis. Thus, we propose that mean CIMT should be measured in all diabetic and metabolic syndrome patients to screen them for possible complications of atherosclerosis, so that timely measures can be taken.

\section{REFERENCES}

[1] George JM, Bhat R, Pai KM, et al. The carotid artery intima media thickness: a predictor of clinical coronary events. Journal of Clinical and Diagnostic Research 2013;7(6):1082-5.

[2] Sahoo AK, Sastry AS, Saga MK. Correlation of carotid artery intima media thickness with atherosclerosis in diabetes. INT J Health Res in Mod Integrt Med Sci (IJHRMIMS0) 2014. ISSN 23948621.

[3] Pujia A, Gnasso A, Irace C, et al. Common carotid artery wall thickness in NIDDM subjects. Diabetes Care 1994;17(11):1330-6.

[4] Jauch EC, Lutsep HL. Ischemic stroke treatment \& management. Updated: Mar 28, 2019.

[5] Hemingway JF, Rowe VL. Atherosclerotic Disease of the carotid artery: treatment \& management. Updated: Feb 21, 2019. 
[6] Sun Y, Lin CH, Lu CJ, et al. Carotid atherosclerosis, intima media thickness and risk factors - an analysis of 1781 asymptomatic subjects in Taiwan. Atherosclerosis 2002;164(1):89-94.

[7] American Diabetes Association. Diagnosis and classification of diabetes mellitus. Diabetes Care 2012;35(Suppl 1):S64-S71.

[8] Doruk H, Mas MR, Ateskan U, et al. The relationship between age and carotid artery intima media thickness, hemoglobin HbA1c in nondiabetic, healthy geriatric population. Archieves of Gerontology and Geriatrics 2008;41(2):113- 9.

[9] Fusaro MF, Zanini JL, Silva IN. Increased carotid intimamedia thickness in Brazilian adolescents with type 1 diabetes mellitus. Diabetol Metabol Syndr 2016;8:74.
[10] Geroulakos G, Ramaswami G, Veller MG, et al. Arterial wall changes in type 2 diabetes mellitus subjects. Diabet Med 1994;11(7):692-5.

[11] Al-Nimer MS, Hussein II. Increased mean carotid intima media thickness in type 2 diabetes mellitus patients with non-blood pressure component metabolic syndrome: a preliminary report. Int $\mathrm{J}$ Diabetes Dev Ctries 2009;29(1):19-22.

[12] Wagenknecht LE, D'Agostino R Jr, Savage PJ, et al. Duration of diabetes and carotid wall thickness. The Insulin Resistance Atherosclerosis Study (IRAS). Stroke 1997;28(5):999-1005. 